\title{
The Usefulness of Magnetic Resonance Fluid Attenuation Inversion Recovery Image for Early Diagnosis of Cerebral Hyperperfusion Syndrome
}

\author{
Jeong Mo Shin, Ik Seong Park \\ Department of Neurosurgery, Bucheon St. Mary's Hospital, College of Medicine, The Catholic University of Korea, Bucheon, Korea
}

Objective: Cerebral hyperperfusion syndrome (CHS) is a post-surgical hemodynamic change that requires accurate diagnosis and comprehensive care. Diagnostic criteria are hyperperfusion state without acute infarction or hemorrhage. However, obtaining the exact hyperemia images is difficult; thus, diagnosis is suggested when any infarction or post-surgical hematomas are excluded. In the present study, magnetic resonance image (MRI) findings indicative of CHS pathophysiology were investigated.

Methods: A retrospective study was performed of patients who underwent superficial temporal to middle cerebral artery anastomosis due to atherosclerotic steno-occlusive disease or moyamoya disease. All patients underwent hemodynamic evaluations, including perfusion MRI, single-photon emission computed tomography (SPECT), and digital subtraction angiography preoperatively and postoperatively. CHS was defined based on the symptoms and radiologic findings.

Results: Among the 172 hemispheres investigated in the present study, CHS occurred in 16 patients (9.3\%). Symptoms of $\mathrm{CHS}$ were seizure, motor weakness, and aphasia. Median symptom onset time was 2.6 days (1-8 days). Brain fluid-attenuated inversion recovery (FLAIR) MRI revealed geographic shape high signal intensity area in the white matter in all patients. Apparent diffusion coefficient (ADC) map showed low signal intensity in the same area, indicating interstitial edema. Perfusion MRI or SPECT images showed variable results for defining CHS.

Conclusion: MR FLAIR image combined with the ADC map is a useful diagnostic tool for CHS in the early stage and can aid in the early treatment of CHS and prevent worsening of symptoms.

Key Words: Cerebral bypass surgery, Cerebral hyperperfusion syndrome, Ischemic cerebrovascular disease, Revascularization

\section{INTRODUCTION}

Cerebral hyperperfusion syndrome (CHS) is a major concern for postoperative complications since superficial temporal artery-middle cerebral artery (STA-MCA) anastomosis was considered the standard treatment for atherosclerotic chronic steno-occlusive disease (ACSD) or moyamoya disease $(\mathrm{MMD})^{8,12,14,21)}$. In recent studies, CHS after STA-MCA anastomosis for MMD was reportedly more frequent than other postoperative complications ${ }^{25)}$. Therefore, early diagnosis and

Corresponding author: Ik Seong Park, MD, PhD

Department of Neurosurgery, Bucheon St. Mary's Hospital, College of Medicine, The Catholic University of Korea,

327, Sosa-ro, Bucheon 14647, Korea

Tel: +82-32-340-7212, Fax: +82-32-340-7391

E-mail: ispahk@gmail.com appropriate management of CHS are essential to achieve a good prognosis of patients undergoing STA-MCA anastomosis ${ }^{4,15,24-26)}$

$\mathrm{CHS}$ is a series of clinical symptoms (e.g., headache, aphasia, hemiparesis, seizure) following revascularization surgery, induced by focal cerebral blood flow (CBF) increase ${ }^{2,7,24,25)}$. Several mechanisms cause CHS. Due to increased CBF with impaired cerebral autoregulation and increased vascular permeability, CHS tends to be accompanied by vasogenic ede$\mathrm{ma}^{2,4)}$ and even by intracranial bleeding ${ }^{1,2,4,19)}$.

Currently, several imaging tools to detect increased CBF are used to diagnose CHS, such as single-photon emission computed tomography (SPECT), enhanced perfusion computed tomography (CT), or magnetic resonance imaging (MRI). SPECT is considered a standard modality ${ }^{2,10,25,26}$. However, it has several limitations and cannot be used as an emergency tool in many hospitals. Furthermore, SPECT must be per- 
formed at the exact moment of hyperemic state ${ }^{10,15,22)}$, otherwise false-negative results are obtained.

MRI fluid-attenuated inversion recovery (FLAIR) is a convenient and powerful modality to detect vasogenic edema that occurs due to CHS. Although hyperemia occurs temporarily, if it is severe enough to induce vasogenic edema, the results can be observed on $\mathrm{MRI}^{2,4)}$. MR FLAIR imaging has the advantage of diagnosing $\mathrm{CHS}$ without performing an examination during the hyperemic state. In addition, differentiating cerebral hyperperfusion from ischemia is not difficult when performed with an apparent diffusion coefficient (ADC) map.

Therefore, whether MRI FLAIR combined with ADC image could be a good diagnostic tool for early detection of CHS after STA-MCA anastomosis was investigated in the present study.

\section{MATERIALS AND METHODS}

\section{Patients and Method}

This study included patients who underwent revascularization surgery due to ACSD or MMD between May 2013 and June 2020 at a single institute. A single surgeon performed STA-MCA anastomosis with/without encephalo-duro-arterio-synangiosis. Among the 231 patients, 84 cases involving acute onset of cerebrovascular occlusion, rapid progression of cerebral infarction, or undergoing additional related procedures (e.g., endovascular treatment, decompressive craniectomy) were excluded. The remaining 172 hemispheres of 147 patients were analyzed.

Digital subtraction angiography (DSA), SPECT, and MRI including, T1/T2 weighted images, enhanced T1, FLAIR, diffusion-weighted imaging (DWI), time of flight (TOF), and enhanced magnetic resonance angiography (MRA) were performed before surgery. Brain CT/CT angiography and MR FLAIR combined with DWI were performed within 1 day after the surgery to assess postoperative complications. In addition, MR perfusion and SPECT were performed within 7 days to assess postoperative perfusion status. Finally, follow-up MR perfusion, SPECT, and DSA scans were obtained 6 months postoperatively. In addition, patients underwent appropriate emergency procedures if they showed neurologic deterioration. All images were qualitatively analyzed.

The surgical method for each patient was determined based on preoperative DSA, SPECT, and perfusion MRI. The donor STA was anastomosed to cortical MCA (M4) in an end-to-side manner with 10-0 nylon. If post-anastomosis flow was confirmed to be less than $50 \%$ of pre-anastomosis flow based on microvascular ultrasonic flowmeter (Charbel micro-flowprobe; Transonics Systems, Inc., Ithaca, NY, USA), additional anastomosis with the remaining donor vessel was performed. Bypass patency in every anastomosis case was confirmed with intraoperative micro-doppler measurement (Nicolet Biomedical, Madison, WI, USA) and indocyanine green angiography.

\section{Assessment of CHS with MR FLAIR and ADC Map}

The diagnosis of CHS in patients showing aggravation of neurologic deterioration in the postoperative period was determined based on the following radiologic findings: (1) the presence of newly identified vasogenic edema, characterized by high signal intensity on the surgically treated hemisphere on both FLAIR and ADC map (Fig. 1), or the presence of focal CBF increase on SPECT or MRI perfusion, (2) confirmation of good patency of anastomosis vessels, and (3) absence of other postoperative complications, such as intracranial hemorrhage highly suspicious of occurring during surgery, ischemic lesions, or infections.

If high signal intensity was observed on FLAIR, which was not present on preoperative images and newly occurred during the postoperative period, two neuroradiologists determined whether the finding was vasogenic edema. The patients confirmed to have vasogenic edema underwent additional perfusion MRI and SPECT. The same neuroradiologists and another nuclear medicine specialist determined if $\mathrm{CBF}$ and other
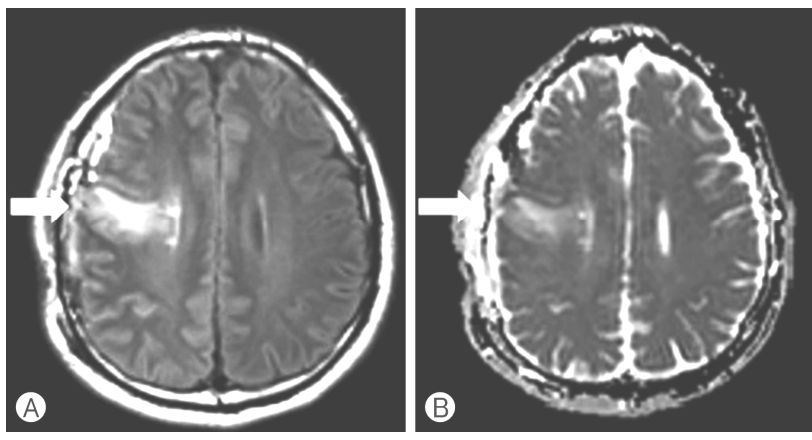

Fig. 1. Postoperative MR FLAIR (A) and ADC (B) images. High signal intensity area was observed on the right frontal lobe (arrow) at postoperative day 1 , indicating vasogenic edema on the FLAIR image. A high signal intensity area was observed on the ADC image (arrow) in the same area, indicating interstitial edema but cerebral infarction. MR FLAIR: magnetic resonance fluid-attenuated inversion recovery, ADC: apparent diffusion coefficient. 
perfusion parameters increased.

\section{Statistical Analysis}

All statistical analyses were performed using IBM SPSS Statistic Subscription program version 1.0.0.14. (IBM Corp., Armonk, NY, USA). Differences between the two groups (CHS/non-CHS or MMD/ACSD) were evaluated using the chi-squared test or Fisher's exact test as appropriate for categorical variables (CHS incidence, sex, operation side, operation method, presentation at the onset, the incidence of permanent neurologic sequelae due to CHS). Age and median onset time of CHS were compared between the groups using the Mann-Whitney $U$ test. A p-value $<0.05$ was considered to indicate statistical significance.

\section{RESULTS}

Among the 172 hemispheres analyzed, CHS occurred in 16 patients (9.3\%) after revascularization surgery; 4 were $\mathrm{MMD}$ patients, and 12 had ACSD. Baseline characteristics including age, sex, operation side, presentation at the onset, and surgi- cal method were reviewed in each CHS and non-CHS group (Table 1). Age was statistically associated with the occurrence of CHS ( $\mathrm{p}=0.007$ ); older patients tended to have a high risk of CHS. Regarding the operation side, CHS occurred more frequently in the left hemisphere but without statistical significance $(\mathrm{p}=0.051)$. No other factors were statistically correlated with the occurrence of CHS.

The clinical data of patients with CHS is listed in Table 2. All initial CHS presentations were TIA (9/16) or cerebral infarction (7/16). CHS did not occur in the hemorrhage presentation group in $\mathrm{MMD}$. All symptoms were completely relieved without permanent cerebral damage in the patient who had only cerebral edema. Two patients had permanent neurologic sequelae due to postoperative intracranial hemorrhage caused by severe CHS.

In the present study, CHS frequently occurred 2 or 3 days and up to 14 days postoperatively (median onset time: 2.5 days). Onset time was different based on the disease: MMD vs. ACSD (4.5 vs. 2 ; Table 3). However, a statistically significant difference was not observed $(\mathrm{p}=0.379)$.

A total of 15 cases $(93.8 \%)$ with CHS showed vasogenic edema in subcortical white matter, characterized by high sig-

Table 1. Baseline characteristics of the 172 hemispheres

\begin{tabular}{|c|c|c|c|c|c|c|c|}
\hline & \multicolumn{3}{|c|}{ Non-CHS } & \multicolumn{3}{|c|}{$\mathrm{CHS}$} & \multirow{2}{*}{ p-value } \\
\hline & Total & MMD & ACSD & Total & MMD & ACSD & \\
\hline Hemispheres & $156(90.7)$ & $66(38.4)$ & $90(52.3)$ & $16(9.3)$ & $4(2.3)$ & $12(7.0)$ & $0.197^{*}$ \\
\hline Age (median, yr) & 50.5 & 37.4 & 60.1 & 61.6 & 49.0 & 65.8 & $0.007^{+}$ \\
\hline Sex & & & & & & & $0.195^{*}$ \\
\hline Male & $85(54.5)$ & $20(30.3)$ & $65(72.2)$ & $6(37.5)$ & $3(75.0)$ & $3(25.0)$ & \\
\hline Female & $71(45.5)$ & $46(69.7)$ & $25(27.8)$ & $10(62.5)$ & $1(25.0)$ & $9(75.0)$ & \\
\hline Operation side & & & & & & & $0.051^{*}$ \\
\hline Right & $79(50.6)$ & $37(56.1)$ & $42(46.7)$ & $4(25.0)$ & $2(50.0)$ & $2(16.7)$ & \\
\hline Left & $77(49.4)$ & $29(43.9)$ & $48(53.3)$ & $12(75.0)$ & $2(50.0)$ & $10(83.3)$ & \\
\hline Presentation at onset & & & & & & & $0.285^{*}$ \\
\hline TIA & $64(41.0)$ & $30(45.5)$ & $34(37.8)$ & $9(56.3)$ & $2(50.0)$ & $7(58.3)$ & \\
\hline Infarction & $76(48.7)$ & $22(33.3)$ & $54(60.0)$ & $7(43.7)$ & $2(50.0)$ & $5(41.7)$ & \\
\hline Hemorrhage & $16(10.3)$ & $14(21.2)$ & $2(2.2)$ & $0(0)$ & $0(0)$ & $0(0)$ & \\
\hline Operation method & & & & & & & $0.075^{\ddagger}$ \\
\hline Direct single & $100(64.1)$ & $21(31.8)$ & $79(87.8)$ & $8(60.0)$ & $1(25.0)$ & $7(58.3)$ & \\
\hline Direct double & $11(7.1)$ & $2(3.0)$ & $9(10.0)$ & $4(20.0)$ & $0(0)$ & $4(33.3)$ & \\
\hline Combined & $45(28.8)$ & $43(65.2)$ & $2(2.2)$ & $4(20.0)$ & $3(75.0)$ & $1(8.3)$ & \\
\hline
\end{tabular}

Values are presented as number (\%) as otherwise indicated.

CHS: cerebral hyperperfusion syndrome, MMD: moyamoya disease, ACSD: atherosclerotic chronic steno-occlusive, TIA: transient ischemic attack, Direct single: superficial temporal artery to middle cerebral artery (STA-MCA) anastomosis, Direct double: STA-MCA anastomosis with two donor artery, Combined: STA-MCA anastomosis with encephalo-duro-arterio-synangiosis.

"chi-squared test, ${ }^{+}$Mann-Whitney U test, ${ }^{\ddagger}$ Fisher-Freeman-Halton exact test. 
nal intensity on both FLAIR and ADC map (Table 3), and in most cases (14/15), except 1 case with no follow-up during the study, high signal intensity was not present on follow-up. Among the 14 cases, 5 (31.3\%) showed focal CBF increase in MR perfusion, and 3 of those cases (21.4\%) showed increased focal uptake on SPECT.

\section{Case 1}

A 73-year-old female who underwent STA-MCA anastomosis for ACSD (No. 15, Table 2) complained of right-side hemiparesis and hypesthesia on postoperative day 2. Typical high signal intensity was observed on MRI FLAIR and ADC. She was given anti-hyperemic care: absolute bed rest, fluid restriction, and treatment to lower systolic blood pressure to less than $120 \mathrm{mmHg}$. Immediate follow-up perfusion MRI and SPECT revealed no significant changes (Fig. 2). All symptoms disappeared without any neurologic deficits within 1 day. The change in high signal intensity was not observed on images at the 6-month follow-up.

\section{Case 2}

A 57-year-old male who underwent a combined bypass for

Table 2. Clinical data of patients with CHS

\begin{tabular}{|c|c|c|c|c|c|c|c|c|c|c|c|c|c|c|}
\hline \multirow[b]{2}{*}{ Case } & \multirow{2}{*}{$\begin{array}{l}\text { Age/ } \\
\text { Sex }\end{array}$} & \multirow[b]{2}{*}{ Diagnosis } & \multirow{2}{*}{$\begin{array}{c}\text { Initial } \\
\text { presentation }\end{array}$} & \multirow[b]{2}{*}{ Direction } & \multirow{2}{*}{$\begin{array}{l}\text { Operation } \\
\text { method }\end{array}$} & \multicolumn{4}{|c|}{$\mathrm{CHS}$} & \multicolumn{2}{|c|}{ MR FLAIR } & \multicolumn{2}{|c|}{$\begin{array}{l}\text { Hyperemia on } \\
\text { MR Perfusion } \\
\end{array}$} & \multirow{2}{*}{$\begin{array}{l}\text { Hyperemia } \\
\text { on SPECT }\end{array}$} \\
\hline & & & & & & Presentation & $\begin{array}{l}\text { Intracranial } \\
\text { hemorrhage }\end{array}$ & $\begin{array}{l}\text { Onset } \\
\text { time } \\
\text { (PODs) }\end{array}$ & $\begin{array}{c}\text { Permanent } \\
\text { neurologic } \\
\text { sequelae }\end{array}$ & $\begin{array}{l}\text { High } \\
\text { SI }\end{array}$ & $\begin{array}{l}\text { SI loss } \\
\text { at } \mathrm{f} / \mathrm{u}\end{array}$ & $\mathrm{CBF}$ & TTP & \\
\hline 1 & $43 / \mathrm{M}$ & MMD & Infarction & Right & Combined & $\begin{array}{l}\text { Limb } \\
\text { weakness }\end{array}$ & $\mathrm{O}$ & 8 & $\mathrm{O}$ & $\mathrm{O}$ & $\mathrm{O}$ & $X$ & $\mathrm{O}$ & $X$ \\
\hline 2 & $31 / \mathrm{F}$ & $\mathrm{MMD}$ & Infarction & Left & Combined & Dysarthria & & 2 & $\mathrm{X}$ & $\mathrm{O}$ & $\mathrm{O}$ & $\mathrm{O}$ & $\mathrm{O}$ & not done \\
\hline 3 & $57 / \mathrm{M}$ & MMD & TIA & Right & $\begin{array}{l}\text { Direct } \\
\text { single }\end{array}$ & $\begin{array}{l}\text { Limb } \\
\text { weakness }\end{array}$ & & 6 & $\mathrm{X}$ & $\mathrm{O}$ & $\mathrm{O}$ & $\mathrm{O}$ & $\mathrm{O}$ & $\mathrm{X}$ \\
\hline 4 & $65 / \mathrm{M}$ & MMD & TIA & Left & Combined & Dysarthria & & 3 & $\mathrm{X}$ & $\mathrm{O}$ & $\mathrm{O}$ & $X$ & $\mathrm{O}$ & $\mathrm{O}$ \\
\hline 5 & $65 / \mathrm{M}$ & $\begin{array}{l}\text { ACSD, } \\
\text { ICA }\end{array}$ & Infarction & Left & $\begin{array}{l}\text { Direct } \\
\text { single }\end{array}$ & Seizure & & 2 & $\mathrm{X}$ & $\mathrm{O}$ & $\mathrm{O}$ & $\mathrm{O}$ & $\mathrm{O}$ & $\mathrm{O}$ \\
\hline 6 & $69 / \mathrm{M}$ & $\begin{array}{l}\text { ACSD, } \\
\text { M1 }\end{array}$ & Infarction & Left & $\begin{array}{l}\text { Direct } \\
\text { double }\end{array}$ & Aphasia & $\mathrm{O}$ & 2 & $\mathrm{X}$ & $\mathrm{O}$ & $\mathrm{O}$ & $X$ & $\mathrm{O}$ & not done \\
\hline 7 & $52 / \mathrm{F}$ & $\begin{array}{l}\text { ACSD, } \\
\text { M1 }\end{array}$ & Infarction & Left & $\begin{array}{l}\text { Direct } \\
\text { double }\end{array}$ & Aphasia & & 1 & $\mathrm{X}$ & $\mathrm{O}$ & $\mathrm{O}$ & $X$ & $\mathrm{O}$ & $\mathrm{X}$ \\
\hline 8 & $72 / \mathrm{F}$ & $\begin{array}{l}\text { ACSD, } \\
\text { M1 }\end{array}$ & Infarction & Right & $\begin{array}{l}\text { Direct } \\
\text { single }\end{array}$ & Hemiparesis & & 8 & $\mathrm{X}$ & $\mathrm{O}$ & $\mathrm{O}$ & $X$ & $X$ & $X$ \\
\hline 9 & $74 / F$ & $\begin{array}{l}\text { ACSD, } \\
\text { M1 }\end{array}$ & Infarction & Left & $\begin{array}{l}\text { Direct } \\
\text { single }\end{array}$ & Aphasia & & 12 & $\mathrm{X}$ & $\mathrm{X}$ & $\mathrm{X}$ & $\mathrm{O}$ & $\mathrm{O}$ & $\mathrm{O}$ \\
\hline 10 & $60 / \mathrm{M}$ & $\begin{array}{l}\text { ACSD, } \\
\text { ICA }\end{array}$ & TIA & Left & Combined & $\begin{array}{l}\text { Limb } \\
\text { weakness }\end{array}$ & $\mathrm{O}$ & 2 & $X$ & $\mathrm{O}$ & $\mathrm{O}$ & $\mathrm{X}$ & $\mathrm{X}$ & $\mathrm{X}$ \\
\hline 11 & $64 / F$ & $\begin{array}{l}\text { ACSD, } \\
\text { ICA }\end{array}$ & TIA & Left & $\begin{array}{l}\text { Direct } \\
\text { single }\end{array}$ & Aphasia & & 1 & $X$ & $\mathrm{O}$ & $\begin{array}{l}\text { not } \\
\text { done }\end{array}$ & $\mathrm{X}$ & $X$ & $\mathrm{X}$ \\
\hline 12 & $70 / \mathrm{F}$ & $\begin{array}{l}\text { ACSD, } \\
\text { ICA }\end{array}$ & TIA & Left & $\begin{array}{l}\text { Direct } \\
\text { single }\end{array}$ & $\begin{array}{l}\text { Limb } \\
\text { weakness }\end{array}$ & $\mathrm{O}$ & 8 & $\mathrm{O}$ & $\mathrm{O}$ & $\mathrm{O}$ & $\mathrm{X}$ & $X$ & $\mathrm{X}$ \\
\hline 13 & $62 / F$ & $\begin{array}{l}\text { ACSD, } \\
\text { ICA }\end{array}$ & TIA & Left & $\begin{array}{l}\text { Direct } \\
\text { double }\end{array}$ & Aphasia & & 3 & $X$ & $\mathrm{O}$ & $\mathrm{O}$ & $X$ & $X$ & $X$ \\
\hline 14 & $56 / \mathrm{F}$ & $\begin{array}{l}\text { ACSD, } \\
\text { M1 }\end{array}$ & TIA & Right & $\begin{array}{l}\text { Direct } \\
\text { double }\end{array}$ & $\begin{array}{l}\text { Limb } \\
\text { weakness }\end{array}$ & & 0 & $X$ & $\mathrm{O}$ & $\mathrm{O}$ & $X$ & $X$ & $X$ \\
\hline 15 & $73 / \mathrm{F}$ & $\begin{array}{l}\text { ACSD, } \\
\text { M1 }\end{array}$ & TIA & Left & $\begin{array}{l}\text { Direct } \\
\text { single }\end{array}$ & $\begin{array}{l}\text { Limb } \\
\text { weakness }\end{array}$ & & 2 & $X$ & $\mathrm{O}$ & $\mathrm{O}$ & $X$ & $X$ & $X$ \\
\hline 16 & $72 / \mathrm{F}$ & $\begin{array}{l}\text { ACSD, } \\
\text { M2 }\end{array}$ & TIA & Left & $\begin{array}{l}\text { Direct } \\
\text { single }\end{array}$ & Seizure & $\mathrm{O}$ & 3 & $X$ & $\mathrm{O}$ & $\mathrm{O}$ & $\mathrm{O}$ & $\mathrm{O}$ & $X$ \\
\hline
\end{tabular}

ACSD: atherosclerotic chronic steno-occlusive disease, CBF: cerebral blood flow on MRI perfusion, CHS: cerebral hyperperfusion syndrome, Combined: STA-MCA anastomosis with encephalo-duro-arterio-synangiosis, Direct single: superficial temporal artery to middle cerebral artery (STA-MCA) anastomo- sis, Direct double: STA-MCA anastomosis with two donor artery, FLAIR: fluid attenuated inversion recovery, ICA: internal carotid artery, M1: middle cerebral artery, Segment 1, M2: middle cerebral artery, Segment 2, MR: magnetic resonance, PODs: postoperative days, SI loss at f/u: signal intensity disappearance at 6-month postoperative follow-up, SPECT: single photon emission computed tomography, TIA: transient ischemic attack, TTP: time-to-peak on MRI perfusion. 
MMD (No. 3, Table 2) complained of left side hemiparesis on postoperative day 6 . High signal intensity change was observed in the operated hemisphere, which did not show definite lesion on a postoperative day $1 \mathrm{MRI}$. CBF and time-to-
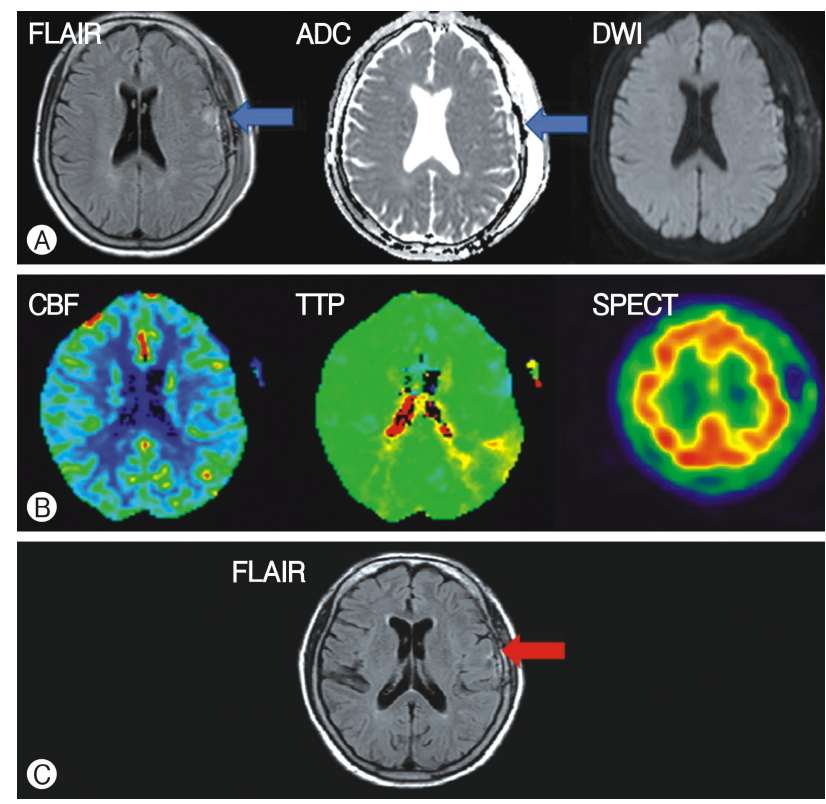

Fig. 2. Radiologic finding in case 1. (A) MR FLAIR with ADC and diffusion at postoperative day 2 showed vasogenic edema characterized by focal high signal intensity on both FLAIR and ADC map (blue arrow). (B) MR perfusion and SPECT on postoperative day 2 showed no significant findings. (C) The disappearance of high signal change on the left hemisphere on the 6-month follow-up MRI (red arrow). MR FLAIR: magnetic resonance fluid-attenuated inversion recovery, ADC: apparent diffusion coefficient, SPECT: single-photon emission computed tomography, DWI: diffusionweighted imaging, CBF: cerebral blood flow, TTP: time-to-peak. peak map also showed significant changes. With anti-hyperemic therapy, neurologic symptoms were completely relieved. The change in high signal intensity was not observed on images at the 6-month follow-up (Fig. 3).
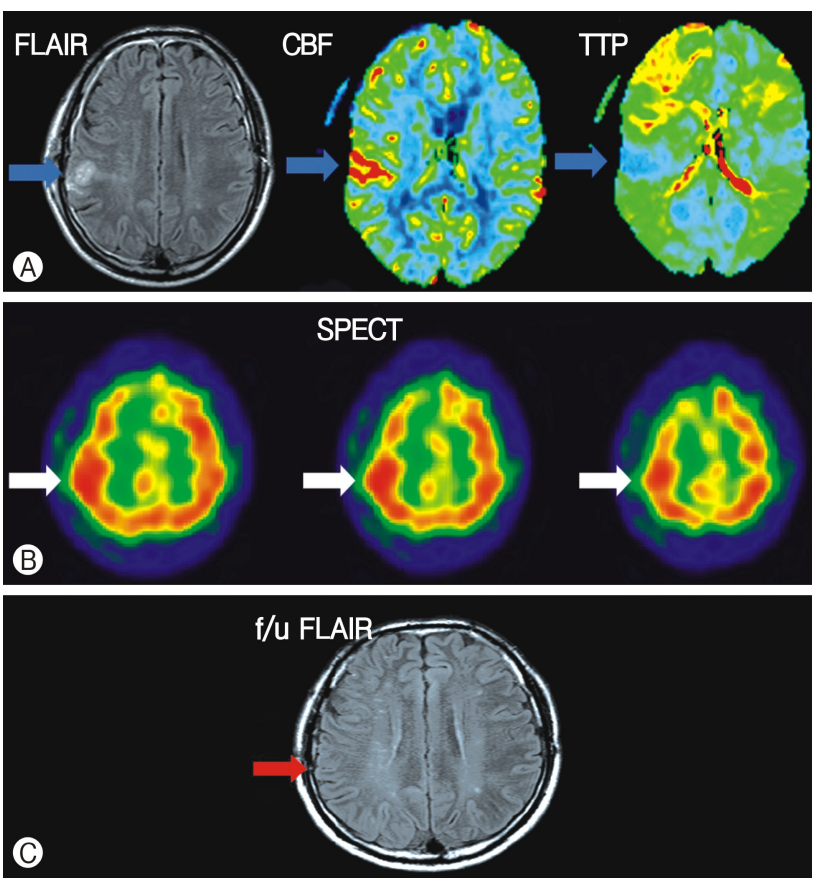

Fig. 3. Radiologic finding in case 2. (A) MR FLAIR and perfusion on a postoperative day 6 showed focal vasogenic edema and increased CBF (blue arrow). (B) SPECT on postoperative day 7 also showed increased focal uptake (white arrow). (C) Total resolution of high signal change on the 6-month follow-up MRI (red arrow). MR FLAIR: magnetic resonance fluid-attenuated inversion recovery, CBF: cerebral blood flow, SPECT: single-photon emission computed tomography, TTP: time-to-peak.

Table 3. Summary of patients with CHS

\begin{tabular}{lcccc}
\hline \hline & \multicolumn{3}{c}{ CHS } & \multirow{2}{*}{ p-value } \\
\cline { 2 - 4 } & Total & MMD & ACSD & \\
\hline CHS incidence (\%) & $16 / 172(9.3)$ & $4 / 70(5.7)$ & $12 / 102(11.8)$ & $0.197^{*}$ \\
Onset time (POD, median) & 2.5 & 4.5 & 2 & $0^{+} .379^{+}$ \\
Permanent neurologic sequelae (\%) & $2 / 16(0.13)$ & $1 / 4(0.25)$ & $1 / 12(0.08)$ & $0.450^{\ddagger}$ \\
Detection rate (\%) & & & \\
FLAIR & $15 / 16(93.8)$ & $4 / 4(100.0)$ & $11 / 12(91.7)$ & \\
CBF & $5 / 16(31.3)$ & $2 / 4(50.0)$ & $3 / 12(25.0)$ & \\
TTP & $9 / 16(56.3)$ & $4 / 4(100.0)$ & $5 / 12(41.7)$ & \\
SPECT & $3 / 14(21.4)$ & $1 / 3(33.3)$ & $2 / 11(18.2)$ & \\
\hline
\end{tabular}

CHS: cerebral hyperperfusion syndrome, MMD: moyamoya disease, ACSD: atherosclerotic chronic steno-occlusive, POD: postoperative day, FLAIR: fluid attenuated inversion recovery, CBF: cerebral blood flow, TTP: time-to-peak on MRI perfusion, SPECT: single photon emission computed tomography.

"chi-squared test, ${ }^{+}$Mann-Whitney U test, ${ }^{\ddagger}$ Fisher's exact test. 


\section{DISCUSSION}

Initially, CHS was recognized as a severe complication following carotid endarterectomy (CEA) and carotid angioplasty and stenting (CAS). However, after Uno et al. ${ }^{23)}$ in 1998 first reported CHS in MMD patients undergoing STA-MCA anastomosis, several studies regarding overall comprehension of CHS after STA-MCA anastomosis have been performed. Yu et el. $^{25)}$ performed a meta-analysis of 27 cohort studies regarding CHS in patients with MMD after revascularization surgery and reported the incidence of CHS after STA-MCA anastomosis for MMD was 16.5\% (range, 11.3-22.3\%), which was more frequent than other postoperative complications, such as infarction/stroke, occlusion, or hypoperfusion of the anastomosis vessel, infection, and other rare complications. Despite the high incidence, CHS usually tends to be transient and neurologic symptoms disappear completely within 14 postoperative days ${ }^{4,710,22,24,25)}$. However, if CHS is not detected and treated on time, intracranial hemorrhage with brain parenchymal damage results and may lead to permanent neurologic complications ${ }^{1,4,19,25)}$.

The exact mechanism of CHS is not fully understood but apparently involves several factors including impaired cerebral autoregulation and increased CBF after revascularization surgery $^{2,24)}$. Hemodynamic compromise with compensatory development of vascular networks, characterized by dilated and thickened vessels in chronic atherosclerotic steno-occlusive disease and $\mathrm{MMD}^{6,11,26}$, causes exhausted cerebrovascular reactivity and impaired cerebral autoregulation ${ }^{2,24,26}$. In addition, oxygen-free radicals produced during reperfusion lead to vasodilation and increased vascular permeability ${ }^{9,16,18,24,26)}$. Postoperative hypertension can aggravate $\mathrm{CHS}^{24)}$. Consequently, a hemodynamically compromised brain does not always respond to revascularization appropriately, and then focal CBF increase with vasogenic edema can occur ${ }^{2,4)}$.

CHS has been defined in many studies as over 100\% increase of CBF compared with preoperative CEA and CAS baseline $^{2,6,19,22,24)}$. However, a consensus is lacking regarding the exact definition of CHS at STA-MCA anastomosis. Currently, several imaging tools are used in most studies to detect relatively increased CBF for the diagnosis of CHS. SPECT is considered a standard modality and widely used for evaluating $\mathrm{CBF}$ and differentiating $\mathrm{CHF}$ from ischemia ${ }^{2,10,25,26}$. However, SPECT has limitations primarily because it is time-consuming, requires radioactive tracer, and cannot be used as an emergency diagnostic in many hospitals. However, cerebral hyperemia can be transient and intermittent, which means imaging tools to evaluate $\mathrm{CBF}$ must be performed at the exact time of hyperemic state or serially to compare states ${ }^{10,15,22)}$. SPECT showed variable results in several studies based on when the imaging was serially performed to evaluate $\mathrm{CBF}^{22}$. In the present study, SPECT and perfusion MRI also showed variable results (Table 3); some patients showed hypoperfusion area despite hyperperfusion syndrome.

In recent studies, the usefulness of other image modalities not directly measuring $\mathrm{CBF}$ for diagnosis of $\mathrm{CHS}$ was reported. Sato et al. ${ }^{20)}$ suggested that TOF-MRA can be useful for screening CHS because the signal intensity of the anastomosis vessel is increased in CHS patients. In the present study, the focus was on vasogenic edema that occurred as a result of CHS. MRI FLAIR with DWI is a convenient tool to detect vasogenic edema and is advantageous because it does not have to be performed at the exact hyperemic state due to remaining vasogenic edema and differentiating cerebral hyperperfusion from ischemia. In the present study, most patients with CHS $(15 / 16,93.8 \%)$ showed high signal intensity in subcortical white matter on both FLAIR and ADC map and usually experienced complete relief without permanent cerebral damage. Follow-up examinations showed the vasogenic edema caused by CHS tended to be resolved, and most patients completely recovered under appropriate treatments. Two patients with prolonged neurologic sequelae had brain parenchymal damage with intracranial hemorrhage caused by the progression of CHS.

In many studies, the significance of early detection and management of CHS before permanent parenchymal damage occurs has been emphasized ${ }^{1,2,4,19,25)}$. Many patients diagnosed with $\mathrm{CHS}$ are treated after CHS becomes symptomatic because of limited accessibility to SPECT. However, in our institute, 6 patients (6/16) were diagnosed and managed with CHS using MR FLAIR on postoperative day 1, before the CHS became symptomatic. The patients did not have permanent neurologic sequelae or brain parenchymal damage on follow-up brain images.

In our institute, patients diagnosed with CHS were managed with generally accepted methods. In many studies, careful monitoring and lowering of blood pressure were reportedly critical $^{2,3,24,25)}$. Definite consensus regarding duration and blood pressure target of antihypertensive treatment is lacking. We carefully lowered systolic blood pressure to 110-130 $\mathrm{mmHg}$ using intravenous labetalol or nicardipine during the 
symptomatic period. Anti-epileptic drugs, corticosteroids, and mannitol were used in selected patients depending on their symptoms and postoperative radiologic images. Free radical scavengers (such as edaravone), which were reported effective against CHS in some studies ${ }^{16}$, were not used due to unavailability in our institute.

Positive findings in this study indicated the presence of vasogenic edema; thus, high signal intensity was mainly present in the subcortical white matter of the surgically-treated hemisphere. Therefore, the 'Ivy sign' which is observed as leptomeningeal high signal intensity on MR FLAIR as a result of dilated pial vessels and slow leptomeningeal flow, and the 'Cortical belt sign' defined as an intraparenchymal belt-like area of high signal intensity in previous studies, were excluded ${ }^{5,13,18)}$.

In the present study, SPECT and MR perfusion for evaluating CBF typically did not show better results in CHS patients than MR FLAIR with ADC map (Table 3). Therefore, comparisons between radiologic modalities should not be made because MR FLAIR/diffusion images were obtained during the examination period of CHS and MR perfusion/SPECT were not.

The present study had several limitations. The radiologic examination schedules were not standardized and varied in each case. In addition, the definition of patients with CHS was somewhat ambiguous in the present study because increased $\mathrm{CBF}$ was not confirmed in all patients who were diagnosed with CHS. As previously mentioned, MR FLAIR with ADC map was primarily used to diagnose CHS and not SPECT. MR perfusion and SPECT were not always performed at the exact occurrence of CHS and showed no significant findings.

\section{CONCLUSION}

MR FLAIR combined with ADC map is a quick and useful tool to diagnose CHS after STA-MCA anastomosis. Consequently, further aggravation of CHS was prevented with early diagnosis and management.

Conflicts of interest: The authors declare that the article content was composed in the absence of any commercial or financial relationships that could be construed as a potential conflict of interest.

\section{REFERENCES}

1. Benzel EC, Hoppens KD: Factors associated with postopera- tive hypertension complicating carotid endarterectomy. Acta Neurochir (Wien) 112:8-12, 1991

2. Farooq MU, Goshgarian C, Min J, Gorelick PB: Pathophysiology and management of reperfusion injury and hyperperfusion syndrome after carotid endarterectomy and carotid artery stenting. Exp Transl Stroke Med 8:7-16. 2016

3. Fujimura M, Inoue T, Shimizu H, Saito A, Mugikura S, Tominaga $\mathrm{T}$ : Efficacy of prophylactic blood pressure lowering according to a standardized postoperative management protocol to prevent symptomatic cerebral hyperperfusion after direct revascularization surgery for moyamoya disease. Cerebrovasc Dis 33:436-445, 2012

4. Fujimura M, Shimizu H, Mugikura S, Tominaga T: Delayed intracerebral hemorrhage after superficial temporal arterymiddle cerebral artery anastomosis in a patient with moyamoya disease: possible involvement of cerebral hyperperfusion and increased vascular permeability. Surg Neurol 71:223-227; discussion 227, 2009

5. Hamano E, Kataoka H, Morita N, et al.: Clinical implications of the cortical hyperintensity belt sign in fluid-attenuated inversion recovery images after bypass surgery for moyamoya disease. J Neurosurg 126:1-7, 2017

6. Hayashi K, Horie N, Suyama K, Nagata I: Incidence and clinical features of symptomatic cerebral hyperperfusion syndrome after vascular reconstruction. World Neurosurg 78: 447-454, 2012

7. Heros RC, Scott RM, Kistler JP, Ackerman RH, Conner ES: Temporary neurological deterioration after extracranial-intracranial bypass. Neurosurgery 15:178-185, 1984

8. Houkin K, Kamiyama H, Abe H, Takahashi A, Kuroda S: Surgical therapy for adult moyamoya disease. Can surgical revascularization prevent the recurrence of intracerebral hemorrhage? Stroke 27:1342-1346, 1996

9. Janigro D, West GA, Nguyen TS, Winn HR: Regulation of blood-brain barrier endothelial cells by nitric oxide. Circ Res 75:528-538, 1994

10. Kaku Y, lihara K, Nakajima N, et al.: Cerebral blood flow and metabolism of hyperperfusion after cerebral revascularization in patients with moyamoya disease. J Cereb Blood Flow Metab 32:2066-2075, 2012

11. Kim JS. Moyamoya Disease: epidemiology, clinical features, and diagnosis. J Stroke 18:2-11, 2016

12. Klopfenstein JD, Ponce FA, Kim LJ, Albuquerque FC, Nakaji P, Spetzler RF: Middle cerebral artery stenosis: endovascular and surgical options. Skull Base 15:175-189, 2005

13. Maeda M, Tsuchida C: "Ivy sign" on fluid-attenuated inversion-recovery images in childhood moyamoya disease. Am J Neuroradiol 20:1836-1838, 1999

14. Miyamoto S, Yoshimoto T, Hashimoto N, et al.: Effects of extracranial-intracranial bypass for patients with hemorrhagic moyamoya disease: Results of the Japan Adult Moyamoya Trial. Stroke 45:1415-1421, 2014

15. Nomura S, Yamaguchi K, Ishikawa T, Kawashima A, Okada Y, Kawamata T: Factors of delayed hyperperfusion and the 
importance of repeated cerebral blood flow evaluation for hyperperfusion after direct bypass for moyamoya disease. World Neurosurg 118:e468-e472, 2018

16. Ogasawara $\mathrm{K}$, Inoue $\mathrm{T}$, Kobayashi $\mathrm{M}$, Endo $\mathrm{H}$, Fukuda $\mathrm{T}$, Ogawa A: Pretreatment with the free radical scavenger edaravone prevents cerebral hyperperfusion after carotid endarterectomy. Neurosurgery 55:1060-1067, 2004

17. Ogasawara K, Sakai N, Kuroiwa T, et al.: Intracranial hemorrhage associated with cerebral hyperperfusion syndrome following carotid endarterectomy and carotid artery stenting: retrospective review of 4,494 patients. J Neurosurg 107:1130 1136, 2007

18. Ohta T, Tanaka H, Kuroiwa T: Diffuse leptomeningeal enhancement, "Ivy sign," in magnetic resonance images of moyamoya disease in childhood: Case report. Neurosurgery 37:1009-1012, 1995

19. Piepgras DG, Morgan MK, Sundt TM, Jr., Yanagihara T, Mussman LM: Intracerebral hemorrhage after carotid endarterectomy. J Neurosurg 68:532-536, 1988

20. Sato K, Yamada M, Kuroda H, et al.: Time-of-flight MR angiography for detection of cerebral hyperperfusion syndrome after superficial temporal artery-middle cerebral artery anas- tomosis in moyamoya disease. Am J Neuroradiol 37:12441248. 2016

21. Smith ER, Scott RM: Surgical management of moyamoya syndrome. Skull Base 15:15-26, 2005

22. Uchino H, Kuroda S, Hirata K, Shiga T, Houkin K, Tamaki $\mathrm{N}$ : Predictors and clinical features of postoperative hyperperfusion after surgical revascularization for moyamoya disease: A serial single photon emission CT/positron emission tomography study. Stroke 43:2610-2616, 2012

23. Uno M, Nakajima N, Nishi K, Shinno K, Nagahiro S: Hyperperfusion syndrome after extracranial-intracranial bypass in a patient with moyamoya disease--Case report. Neurol Med Chir (Tokyo) 38:420-424, 1998

24. van Mook WN, Rennenberg RJ, Schurink GW, et al.: Cerebral hyperperfusion syndrome. Lancet Neurol 4:877-888, 2005

25. Yu J, Zhang J, Li J, Zhang J, Chen J: Cerebral hyperperfusion syndrome after revascularization surgery in patients with moyamoya disease: Systematic review and meta-analysis. World Neurosurg 135:357-366.e4, 2020

26. Zhao WG, Luo Q, Jia JB, Yu JL: Cerebral hyperperfusion syndrome after revascularization surgery in patients with moyamoya disease. Br J Neurosurg 27:321-325, 2013 